\title{
Anabases
}

ANABASES Traditions et réceptions de l'Antiquité

$20 \mid 2014$

Varia

\section{Sophie KESSLER-MESGUICH [posthume], Les Études hébraïques en France de François Tissard à Richard Simon (1508-1680)}

\section{Luigi-Alberto Sanchi}

\section{(2) OpenEdition}

1 Journals

Édition électronique

URL : http://journals.openedition.org/anabases/5184

DOI : 10.4000/anabases. 5184

ISSN : 2256-9421

Éditeur

E.R.A.S.M.E.

\section{Édition imprimée}

Date de publication : 1 novembre 2014

Pagination : 420-421

ISSN : 1774-4296

\section{Référence électronique}

Luigi-Alberto Sanchi, « Sophie keSsLer-MESGUich [posthume], Les Études hébraïques en France de

François Tissard à Richard Simon (1508-1680) », Anabases [En ligne], 20 | 2014, mis en ligne le 01 novembre 2014, consulté le 22 septembre 2020. URL : http://journals.openedition.org/anabases/5184 ; DOI : https://doi.org/10.4000/anabases.5184

Ce document a été généré automatiquement le 22 septembre 2020

(c) Anabases 


\title{
Sophie KESSLER-MESGUICH [posthume], Les Études hébraïques en France de François Tissard à Richard Simon (1508-1680)
}

\author{
Luigi-Alberto Sanchi
}

\section{RÉFÉRENCE}

Sophie KESSLER-MESGUICH [posthume], Les Études hébraïques en France de François Tissard à Richard Simon (1508-1680), Avant-propos de Max Engammare, Genève, Librairie Droz, Travaux d'Humanisme et Renaissance 517, 2013, $311 \mathrm{p}$.

58 euros / ISSN 0082-6081

1 Il convient de saluer la parution de ce lumineux volume sur les hébraïsants chrétiens en France à la Renaissance, issu d'une thèse de doctorat soutenue en 1994 dans le sillon des travaux de François Secret, revue et enrichie dans les années suivantes. Pris en charge par M. Engammare (voir l'Avant-propos, p. VII-X), Les Études hébraïques en France présente en forme éditée les contenus de l'exemplaire de travail de l'Auteur, la regrettée Sophie Kessler-Mesguich (1958-2010), grande spécialiste des études hébraïques et directrice du Centre de recherche français à Jérusalem, que le public plus large connaît déjà pour sa généreuse initiation L'Hébreu biblique, en quinze leçons (Rennes, PUR, 2008).

2 On sait la place que tient l'hébreu dans l'humanisme chrétien d'Europe et particulièrement en France et à Paris, centre médiéval de rayonnement de la théologie catholique où l'humanisme atténue certains traits néo-païens acquis en Italie pour s'attaquer plus franchement, à l'exemple d'un Pic ou d'un Valla, à la question linguistique, philologique, religieuse, théologique - du christianisme et de ses sources, grecques comme hébraïques, certes avec un retard par rapport aux domaines italien et 
germanique et malgré des résistances et des oppositions traditionalistes qui se manifesteront depuis l'Affaire Reuchlin (1511) jusqu'au procès au Lecteurs royaux de grec et d'hébreu (1533) et au-delà, dans le climat de la Contre-Réforme. L'Auteur choisit pour point d'aboutissement l'Histoire critique du Vieux Testament de Richard Simon (1678), monument de l'approche critique.

3 La première section, " Pourquoi étudie-t-on l'hébreu ? ", p. 14-26, du chapitre I (" L'enseignement de l'hébreu en France ») aborde les principaux aspects de la question, avant de céder la place à une étude fouillée de l'enseignement concret qui a pu être dispensé à Paris, depuis l'époque médiévale (section 2) jusqu'au Grand Siècle, en passant par les pionniers locaux François Tissard et Jean Cheradame ${ }^{3}$, les lecteurs royaux Agathias Guidacier et Paul Paradis, les académies protestantes et les écoles jésuites, à Paris mais aussi à Louvain, autre grand centre de l'humanisme chrétien. Dans ce chapitre comme dans l'ensemble du volume, la clarté du propos sert l'ampleur des recherches et aère la densité des informations apportées.

4 Après la vue panoramique de la section 3, "Enseignants et étudiants d'hébreu (1500-1680) », p. 36-55, l'Auteur se concentre sur quelques ensembles significatifs : la production et la diffusion de livres pour l'enseignement en milieu non-juif (chap. II, « Impression et diffusion des grammaires hébraïques ", p. 57-77, et III, "L'Alphabetum hebraicum, caractéristiques et évolution », p.79-97), l'enseignement du pionnier François Tissard (p. 99-120) et le magistère de Sante Pagnini (1470-1536), premier traducteur - très littéral - de la Bible en latin après saint Jérôme (1527), auteur des Hebraicae Institutiones en 1526 et du Thesaurus linguae sanctae en 1529, ouvrages publiés tous en France (p.121-151). Deux autres monographies, les chap. VI et VII, sont consacrées à des ensembles, le Collège trilingue de Louvain, avec Nicolas Clénard et Jean Campensis (p. 153-169) et celui des Lecteurs royaux à Paris (p. 171-193), abordant à chaque fois les méthodes grammaticales déployées pour enseigner l'hébreu à travers le latin à un public humaniste extérieur aux écoles judaïques traditionnelles.

Préparent la "Conclusion générale » (p. 225-229) deux essais de synthèse, à savoir le chap. VIII abordant le XVI ${ }^{e}$ siècle hébraïsant " de 1500 à $1570 »(p .195-211)$ et le chap. IX, sur "Le Dix-septième siècle " (p. 213-223), où la grammaire et la lexicographie hébraïque perdent leur rôle novateur pour devenir un instrument au service de l'exégèse dans les écoles de théologie, tandis que se dessine l'essor scientifique des grammaires comparées. Parmi les Annexes (p. 233-278, la bibliographie occupant les p. 279-297), on appréciera la liste mise à jour de grammaires publiées en France de 1509 à 1650, riche de soixante et onze éditions (p. 235-243), celle des " Alphabets » en France, de 1514 à 1600, avec trente éditions (p. 244-248), ainsi que la description détaillée des exemplaires étudiés les plus importants, au nombre de vingthuit (p. 249-276). 


\section{NOTES}

3. Signalons aussi l'existence d'études récentes, concernant l'enseignement du grec, sur Tissard, Cheradame et Aléandre (pour son activité parisienne), notamment dans le recueil de monographies établies par J.-F. Maillard et J.-M. Flamand, La France des Humanistes. Hellénistes, t. II, Turnhout, Brepols 2011.

\section{AUTEURS}

\section{LUIGI-ALBERTO SANCHI}

Institut d'Histoire du Droit

luigi-alberto.sanchi@u-paris2.fr 